\title{
Activated eosinophils and interleukin 5 expression in early recurrence of Crohn's disease
}

\author{
S Dubucquoi, A Janin, O Klein, P Desreumaux, P Quandalle, A Cortot, M Capron, \\ J-F Colombel
}

Service d'A Pathologiques, Hôpital Calmette, Centre Hospitalier Régional et Universitaire, Lille, France

S Dubucquoi

A Janin

Service des Maladies de l'Appareil Digestif et de la Nutrition, Hôpital Huriez, Centre Hospitalier Régional et Universitaire, Lille,

France

O Klein

P Desreumaux

A Cortot

J-F Colombel

Service de Chirurgie Adulte Ouest, Hôpital Huriez, Centre Hospitalier Régional et Universitaire, Lille,

France

P Quandalle

Centre d'Immunologie et Biologie Parasitaire, Institut Pasteur,

INSERM U167, Lille, France

$S$ Dubucquoi

M Capron

Correspondence to:

Professor J F Colombel

Service des Maladies de

l'Appareil Digestif et de la

Nutrition, Hôpital Huriez,

Centre Hospitalier Régional

et Universitaire, Lille, 59037

France.

Accepted for publication

19 December 1994

TABLE I Clinical data and surgical indications in patients with Crohn's disease

\begin{tabular}{lllll}
\hline Patients & Age/sex & Years of evolution & Extent of disease & Surgical indications \\
\hline 1 & $35 / \mathrm{F}$ & 0 & Ileum & Fistula \\
2 & $35 / \mathrm{F}$ & 1 & Ileum & Stenosis \\
3 & $40 / \mathrm{F}$ & 1 & Ileum & Stenosis \\
4 & $32 / \mathrm{F}$ & 11 & Ileum & Stenosis \\
5 & $44 / \mathrm{M}$ & 24 & Ileum & Stenosis \\
6 & $23 / \mathrm{M}$ & 1 & Ileum & Medical treatment failure \\
7 & $22 / \mathrm{F}$ & 1 & Ileocolon & Fistula \\
8 & $29 / \mathrm{F}$ & 3 & Colon & Fistula \\
9 & $27 / \mathrm{M}$ & 7 & & \\
\hline
\end{tabular}

resection and ileocolonic anastomosis: rates of endoscopic and clinical recurrences reached $73 \%$ and $33 \%$ at three months and $93 \%$ and $37 \%$ at one year respectively. Finally, in a placebo controlled trial of Claversal in the prevention of early endoscopic relapse, a $63 \%$ endoscopic recurrence rate at three months in 52 patients of the placebo group was found. ${ }^{3}$

The multiple gut involvements in non-operated patients with Crohn's disease make it difficult to analyse easily the early pathological events leading to the inflammatory process. A prospective study of early immunopathological lesions occurring after 'curative' ileal resection and ileocolonic anastomosis was thus undertaken. This study focused on eosinophils, as these cells are present not only in early endoscopic recurrences, ${ }^{4}$ but also throughout the different evolutive stages of Crohn's disease. ${ }^{5}$ Activated eosinophils release specific cationic proteins such as major basic protein and eosinophil cationic protein, which are cytotoxic for a variety of target cells, including intestinal epithelial cells. ${ }^{6}$ Among other factors, interleukin 5 (IL 5) represents the most potent cytokine for eosinophil recruitment and activation. ${ }^{78} \mathrm{We}$ therefore assessed, in early Crohn's disease endoscopic relapses, the magnitude of infiltration by eosinophils, the state of their activation, and simultaneously the mucosal expression of IL 5 .

\section{Methods}

\section{Patients}

From November 1991 to July 1992, nine patients with Crohn's disease (six women, three men, mean age 33 years, range 22-44) having had an ileocolectomy for Crohn's disease and ileocolonic anastomosis underwent two successive ileoscopies (Table I). The first one was performed during the initial surgical procedure and the second one three months later. All patients gave their informed consent after approval of the project by the local ethical committee. In all patients, the diagnosis of Crohn's disease was established on the usual clinical, radiological, endoscopic, and histological grounds. All patients had surgery because of complications - that is, symptomatic stenosis (four cases), fistula (four cases), and medical treatment failure (one case). If patients were taking corticosteroids before surgery, the drug was tapered and stopped within four weeks before operation. No further specific medical treatment - that is, corticosteroids, salicylates, antibiotics, immunosuppressive drugs was prescribed between surgery 
TABLE II Endoscopic and symptomatic recurrences in the nine patients with Crohn's disease, three months after right ileocolectomy and ileocolonic anastomosis

\begin{tabular}{llll}
\hline Patient & $\begin{array}{l}\text { Endoscopic } \\
\text { recurrence }\end{array}$ & $\begin{array}{l}\text { Distance of } \\
\text { anastomosis }(\mathrm{cm})\end{array}$ & $\begin{array}{l}\text { Symptomatic } \\
\text { relapse }\end{array}$ \\
\hline 1 & $\mathrm{i}_{1}$ & 15,30 & No \\
2 & $\mathrm{i}_{1}$ & 10 & No \\
3 & $\mathrm{i}_{3}$ & $0-30$ & No \\
4 & $\mathrm{i}_{1}$ & 7 & No \\
5 & $\mathrm{i}_{2}$ & 2 & No \\
6 & $\mathrm{i}_{1}$ & 5 & No \\
7 & $\mathrm{i}_{0}$ & - & No \\
8 & $\mathrm{i}_{0}$ & - & No \\
9 & $\mathrm{i}_{0}$ & - & \\
\hline
\end{tabular}

^Rutgeerts's criteria. $\mathrm{i}_{0}$ : no endoscopic lesion; $\mathrm{i}_{1}$ : less than five aphtous lesions; $\mathrm{i}_{2}$ : more aphtous lesions but normal mucosa between the lesions or a few skip areas, or larger lesions, or lesions confined to the ileocolonic anastomosis (that is, $<1$ $\mathrm{cm}) ; i_{3}$ : diffuse aphtous ileitis with diffusely inflamed mucosa; $\mathrm{i}_{4}$ : diffuse inflammation with already larger ulcers, nodules, or narrowing, or all three.

and the endoscopy at three months, but antidiarrhoeal and antispasmodic drugs were permitted. Three months after surgery, clinical and endoscopic examinations were performed. Endoscopic recurrence was assessed according to Rutgeerts' criteria, ${ }^{1}$ and macroscopic lesions were biopsied. Furthermore, four biopsies were systematically performed, 10 and $20 \mathrm{~cm}$ above the anastomosis in macroscopically normal mucosa.

Control samples from endoscopically normal small intestine were collected by the same method in seven patients (one woman, six men, mean age 71 years, range 63-79), operated on for carcinoma of the right colon. Control specimens were taken during time of surgery in five patients, six months after right ileocolectomy in one patient, and two years after in the last one.

\section{Pathological study}

Intestinal biopsy specimens were immediately cut into two parts. One was fixed in paraformaldehyde $4 \%$ in cacodylate buffer, and embedded in paraffin wax for histological study, and in situ hybridisation. The other one was fixed in glutaraldehyde $1 \%$ and further processed for electron microscopy. Paraffin wax sections were stained with haematoxylin and eosin and May-Grunwald Giemsa (MGG). Cell counts were systematically performed at magnification 250 on three different areas of the mucosal surface. The results were expressed as a mean number of cells per field. The density of inflammatory infiltrate was graded as 0 : no infiltrate, + : mild infiltrate (less than 150 cells per field at magnification 250 ), ++ : moderate infiltrate (150 to 300 cells per field at magnification 250 ), +++ : dense infiltrate (more than 300 cells per field at magnification 250). Eosinophils were systematically counted on MGG stains at the same magnification of 250 . The results were expressed as the mean number of eosinophils seen in three different fields. Lysis of eosinophils was analysed ultrastructurally, and graded as $0:$ no lysis, $+:$ lysis of less than $50 \%$ of eosinophils, ++ : lysis of more than $50 \%$ of eosinophils. When it was possible 30 cells per section were analysed for each patient.
In situ hybridisation

In situ hybridisation was performed as previously described. ${ }^{9}$ Briefly, the cDNA for human IL 5 was subcloned into the Blue Script vector by standard techniques. Linearised plasmid was used as the template for the synthesis in vitro of a ${ }^{35} \mathrm{~S}$ labelled RNA probe (Amersham-France, Les Ullis, France) complementary to the cellular IL $5 \mathrm{mRNA}$ (antisense probe). RNA was also transcribed in the opposite direction and used as a negative control (sense probe). Antisense or sense probes $\left(4150 \mathrm{cpm} / \mathrm{mm}^{2}\right)$ were hybridised with intestinal samples. To inhibit non-specific binding of ${ }^{35} \mathrm{~S}$, tissues were acetylated in triethanolamine $0.1 \mathrm{M}$, then in acetic anhydride $0.25 \%$ triethanolamine for 10 minutes before hybridisation. Further to avoid non-specific binding to eosinophils, prehybridisation was carried out with a solution containing a non-radiolabelled S-UTP irrelevant probe for at least two hours at $42^{\circ} \mathrm{C}$, dithiotreitol was added to the hybridisation buffer, and ribonuclease $\mathrm{A}$ was used for posthybridisation washings. After development of the emulsion, tissue sections were then stained with MGG for examination by light microscopy. Specific hybridisation was recognised as clear dense deposits of silver grains in the photographic emulsion overlaying the tissue sections. The counts of labelled cells were performed at magnification 1000, and the results were expressed as a mean percentage of labelled cells counted on 200 cells of the lamina propria.

\section{Results}

\section{Recurrences}

None of the nine patients had clinical relapse at three months while endoscopic recurrences occurred in the neoileum above anastomosis in six of nine patients $(66 \%)$ (Table II). In all controls, the mucosa was endoscopically normal.

\section{Pathological examination}

Table III summarises the histological analysis of diseased and endoscopically normal areas in the nine patients with Crohn's disease, performed at three months after right ileocolectomy and ileocolonic anastomosis.

In the six patients with endoscopic relapse (patients $1,2,3,4,5,6$ ), the inflammatory infiltrate was dense in the recurrence areas (Fig 1 ), whereas it was moderate (five of six) or mild (one of six) in the endoscopically normal areas. In the three patients without endoscopic relapse (patients $7,8,9$ ), the inflammatory infiltrate was similar to the one seen in the uninvolved areas of the six patients with early recurrences. In the control specimens, the inflammatory infiltrate was mild.

The counts of eosinophils were higher in recurrence areas (mean 83; range 63-111) than in the endoscopically normal mucosa of both patients with endoscopic recurrences (mean 26; range 21-33) or without endoscopic recurrences. In the normal small intestinal biopsy specimens of controls, the counts of 
TABLE III Histological analysis of lesions and systematic biopsy specimens in the nine patients with Crohn's disease three months after right ileocolectomy and ileocolonic anastomosis and in controls

\begin{tabular}{|c|c|c|c|c|c|c|}
\hline \multirow[b]{2}{*}{ Patient } & \multicolumn{2}{|c|}{$\begin{array}{l}\text { Density of inflammatory } \\
\text { infiltrate }\end{array}$} & \multicolumn{2}{|c|}{ Eosinophil counts } & \multicolumn{2}{|c|}{ Eosinophil lysis } \\
\hline & Lesion & $\begin{array}{l}\text { Normal } \\
\text { mucosa }\end{array}$ & Lesion & $\begin{array}{l}\text { Normal } \\
\text { mucosa }\end{array}$ & Lesion & $\begin{array}{l}\text { Normal } \\
\text { mucosa }\end{array}$ \\
\hline \multicolumn{7}{|c|}{ Crohn's disease with early recurrence } \\
\hline 1 & +++ & ++ & 105 & 34 & + & 0 \\
\hline 2 & +++ & + & 73 & 23 & + & 0 \\
\hline 3 & +++ & ++ & 111 & 32 & ++ & 0 \\
\hline 4 & +++ & ++ & 75 & 23 & + & 0 \\
\hline 5 & +++ & ++ & 83 & 28 & + & 0 \\
\hline 6 & +++ & ++ & 63 & 22 & + & 0 \\
\hline \multicolumn{7}{|c|}{ Crohn's disease without early recurrence } \\
\hline 7 & - & ++ & - & 33 & - & 0 \\
\hline 8 & - & + & - & 21 & - & 0 \\
\hline 9 & - & ++ & - & 23 & - & 0 \\
\hline \multicolumn{7}{|c|}{ Controls (colonic carcinoma) } \\
\hline 1 & - & + & - & 2 & - & 0 \\
\hline 2 & - & + & - & 4 & - & 0 \\
\hline 3 & - & + & - & 1 & - & 0 \\
\hline 4 & - & + & - & 2 & - & 0 \\
\hline 5 & - & + & - & 4 & - & 0 \\
\hline 6 & - & + & - & 1 & - & 0 \\
\hline 7 & - & + & _- & 1 & - & 0 \\
\hline
\end{tabular}

The density of inflammatory infiltrate was graded as: $0:$ no infiltrate, $+:$ mild infiltrate (less than 150 cells per field at magnification 250$),++$ : moderate infiltrate ( 150 to 300 cells per field at magnification 250 ), +++ dense infiltrate (more than 300 cells per field at magnification 250 ). magnification 250$),+++$ dense infiltrate (more than 300 cells per field at magnification 250 ). fields at magnification 250. Lysis of eosinophils was graded as 0: no lysis, +t: lysis of less than fields at magnification 250 . Lysis of eosinophils was graded as $0:$
$50 \%$ of eosinophils, $++:$ lysis of more than $50 \%$ of eosinophils.

eosinophils were always lower than five eosinophils per field.

Eosinophil lysis was only seen in diseased areas and not in endoscopically normal areas of patients with or without endoscopic recurrences. In intestinal biopsy specimens of controls no lytic eosinophil could be seen.

Ultrastructural study of eosinophil changes in samples of diseased mucosa, showed two types of fine structural changes. Some eosinophils had nuclear necrosis with complete cytoplasm lysis and numerous free granules in the extracellular space (Fig 2 left). Others had only granular changes with an inverted density of the central core or tubulovesicular structures (Fig 2 right), and numerous cytoplasmic lipid bodies. The epithelial or endothelial cells surrounding altered eosinophils were not necrotic. Cytoplasmic contacts between eosinophils and lymphocytes, plasma cells, or mast cells were numerous (not shown).

\section{In situ hybridisation}

Cells infiltrating intestinal sections showed

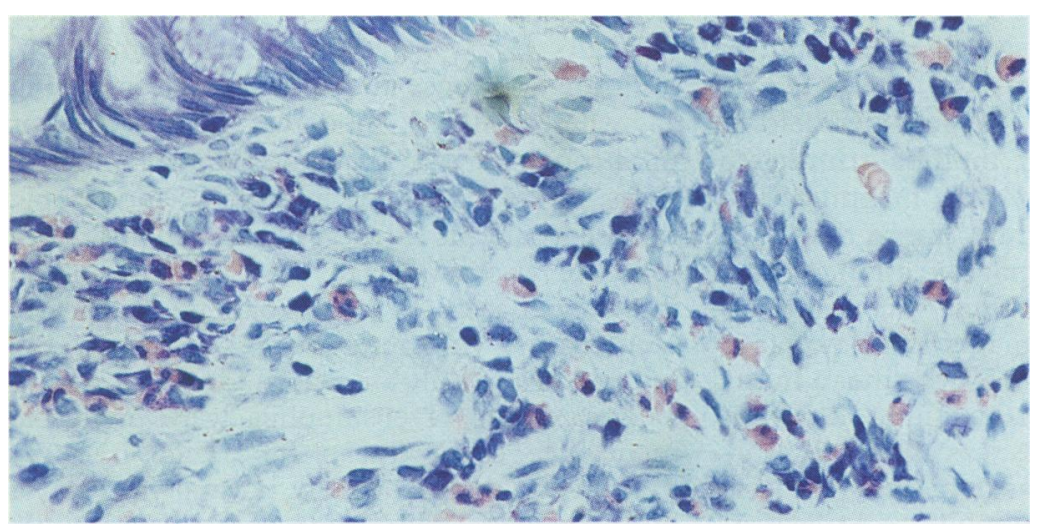

Figure 1: Dense inflammatory infiltrate in diseased mucosa, three months after right ileocolectomy, in a patient with Crohn's disease who relapsed. After May-GrünwaldGiemsa stain, eosinophils appeared red and scattered in the inflammatory infiltrate. In this Figure the eosinophils count is 52 per field $(\times 400)$ (patient 1$)$. positive in situ hybridisation with the IL 5 antisense probe. Positive labelling was only seen in recurrence areas at three months (mean $16.5 \%$ of positive cells, range 7-28) (Fig 3 left). The labelled cells were not identified on these sections. In endoscopically normal areas of both Crohn's disease patients and controls, less than $0.9 \%$ of cells were positive (range $0-2$ ). The control sense probe did not hybridise on the sequential sections (Fig 3 right).

\section{Discussion}

In this series of patients, there was a $66 \%$ rate of endoscopic relapses at three months in patients having an ileocolectomy for Crohn's disease in accordance with previous results. ${ }^{1-3}$ Early recurrence after surgery is one of the best fitted situations for studying the pathogenesis of initial lesions of Crohn's disease. Areas of endoscopic recurrence were characterised by a dense inflammatory infiltrate with numerous eosinophils presenting structural changes: some cells appeared lytic with release of partly changed granules, whereas other cells showed granular changes with disappearance of granule central core.

The detection of numerous eosinophils presenting such changes in areas of endoscopic recurrence suggest their participation in the early mucosal damage in Crohn's disease. Previous studies have reported that morphological changes, and degranulation are associated with activation of blood and tissue eosinophils in eosinophil related diseases. ${ }^{1011} \mathrm{In}$ particular, fading of the central core of numerous eosinophils found in intestinal mucosa, has been linked to release of major basic protein in chronic inflammatory bowel diseases, such as coeliac disease, or eosinophilic gastroenteritis. ${ }^{12}$ ${ }^{13}$ Such evidence of eosinophil activation with release of major basic protein and eosinophilic cationic protein has been previously reported in surgical specimens of patients with Crohn's disease. ${ }^{51415}$ In vitro, eosinophil cationic proteins are able to exert cytotoxicity against epithelial cells and parasites. ${ }^{6} 16$

Activated eosinophils could participate in mucosal lesions in two ways: (a) by a direct cytotoxic effect, or (b) by the recruitment of other inflammatory cells. In this study, the systematic ultrastructural analysis performed on specimens of diseased mucosa did not show any sign of necrosis on cells surrounding or in contact with activated eosinophils. Such a discrepancy between the ultrastructural changes of activation and cytotoxic effects of eosinophils has already been seen in other conditions. In eosinophilic granuloma of bone and chronic eosinophilic pneumonia, eosinophils were lysed and released cationic proteins, which were phagocytosed and concentrated in bone or alveolar macrophages. This interaction, however, between eosinophils and macrophages did not lead to necrosis of the phagocytic cells. ${ }^{1718} \mathrm{~A}$ previous in vitro study showed a similar mechanism of noncytotoxic activation in a model of interaction between neutrophils and eosinophil major basic protein. ${ }^{19}$ 


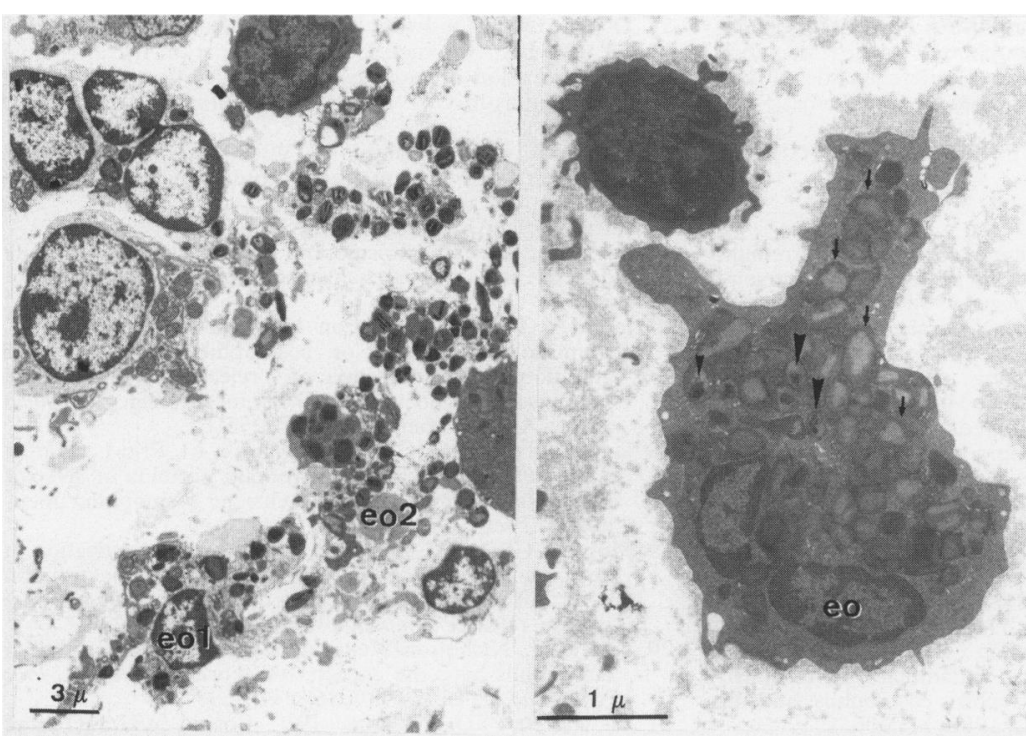

Figure 2: Ultrastructural aspect of eosinophils in diseased mucosa, three months after right ileocolectomy, in a patient with Crohn's disease who relapsed. (Left) Eosinophils show signs of cytoplasmic disaggregation, without nuclear lysis (Eo1), or cytoplasmic and nuclear lysis with free granules in the extracellular space (Eo2) $(\times 4150)$. (Right) Other eosinophils had only granular changes with inverted density core (arrows), and tubulovesicular structures (arrowheads) ( $\times 22$ 750).

It is possible that activated eosinophils in early lesions of Crohn's disease might act by interaction with other inflammatory cells. Eosinophils express the class II major histocompatibility complex, ${ }^{20} 21$ have the capacity to synthesise numerous cytokines, ${ }^{22}$ and might thus serve as antigen presenting cells, as well as a source of growth and regulatory factors.

The mechanism of eosinophil recruitment and activation in Crohn's disease is unknown but an important role of IL 5 is probable. This study showed the presence of IL $5 \mathrm{mRNA}$ in early Crohn's lesions, whereas no IL 5 synthesis was seen in endoscopically normal areas of both Crohn's disease patients or controls.

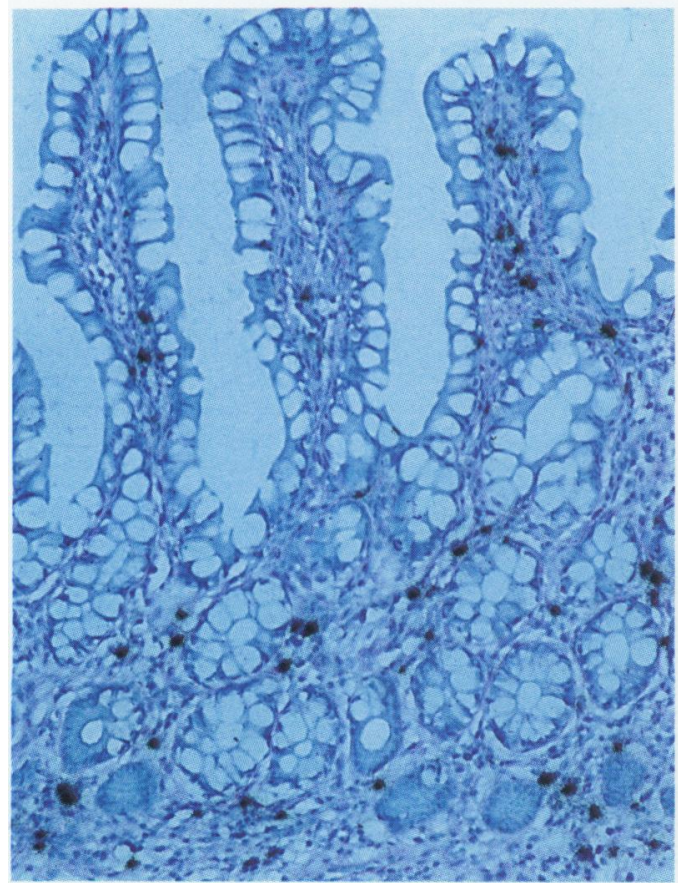

IL 5 is the main mediator for eosinophil recruitment and activation. ${ }^{6} 7$ IL 5 supports the proliferation and terminal differentiation of eosinophilic precursors as well as the prolonged survival of eosinophils in vitro. It is also a selective chemotactic agent for eosinophils and a potent activator of eosinophil functions such as cytotoxicity or mediator release.

Some previous studies have shown increased numbers of IL 2 and IFN $\gamma$ secreting cells in Crohn's disease. ${ }^{23}$ These studies have concluded that a Th1 like profile of lymphokine production may exist in the mucosal lesions of Crohn's disease. The Th1 type of cell is thought to be important in delayed type hypersensitivity reactions, and is more associated with granuloma formation. ${ }^{24}$ Conversely, in this model of early recurrence, presence of eosinophils, which might be attracted and activated through the synthesis of IL 5, favour a Th2 like profile in early mucosal lesions of Crohn's disease. Recent studies have also shown Th2 type of cells in active lesions of inflammatory bowel disease. ${ }^{25}$ In animal models of granuloma formation, different profiles of cytokine production could be seen. In mice infected with Leishmania donovani, IL 2 and IFN $\gamma$ are expressed in the tissues during granuloma formation, ${ }^{26}$ whereas in mice infected by Schistosoma mansoni, data suggest that Th2 cells play an important part in granuloma surrounding eggs. ${ }^{27}$ Previous studies have shown that cytokine profiles might change with the stage of disease. In agreement with these findings, it has been shown in a model of experimental colitis that IL 2 activity was higher in chronic than in acute lesions. ${ }^{28}$ Studies are in progress to ascertain if different patterns of cytokine production may be seen in the different evolutive stages of Crohn's disease.

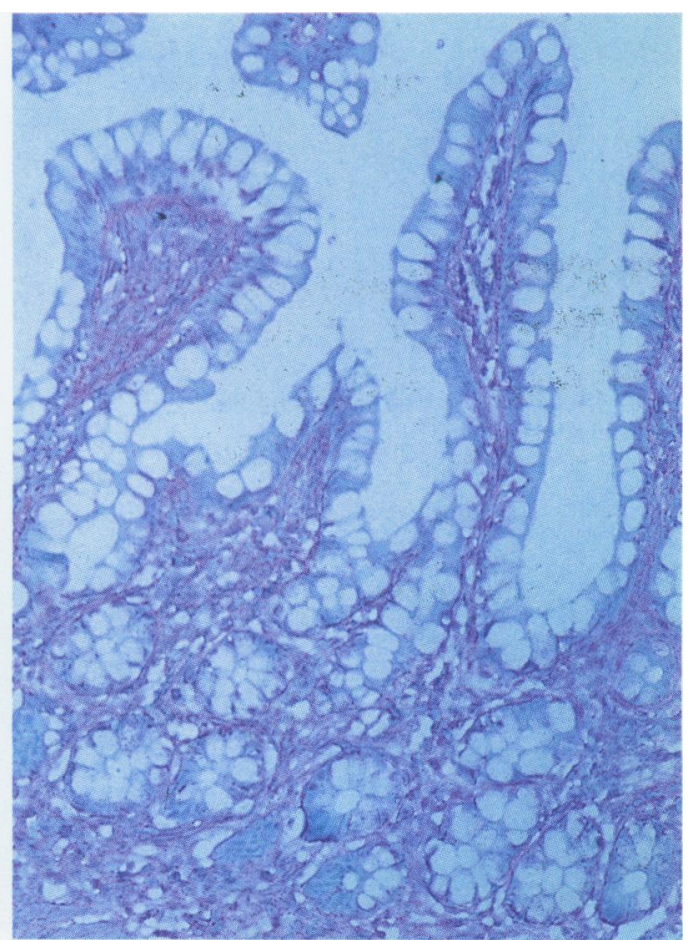

Figure 3: In situ hybridisation with IL 5 mRNA probe on intestinal sections performed in a patient with Crohn's disease, three months after right ileocolectomy. (Left) Positive labelling was seen only in biopsy specimens of patients with recurrent Crohn's disease at three months ( $\times 250)$. (Right) Control with the sense control probe on the same sections: no labelling is seen $(\times 250)$. 
The authors thank Miss L Duflos and Mr A Plockyn for technical assistance. The work has been supported by the Association François Aupetit, The Direction de la Recherche et des Etudes Doctorales (Ministère de l'Enseignement Supérieur), The Rectorales Clinique INSERM, no 492003 and the Comité Réseau Clinique INSERM, no 492003 and the Comite
Directeur Hospitalo-Universitaire pour la Recherche (CH et U de Lille, Contrat 93-02).

1 Rutgeerts P, Geboes K, Vantrappen G, Beyls J, Kerremans $R$, Hiele $M$. Predictability of the postoperative course of Crohn's disease. Gastroenterology 1990; 99; 956-63.

2 Olaison G, Smedh K, Sjodahl R. Natural course of Crohn's disease after ileocolic resection: endoscopically visualised ileal ulcers preceeding symptoms. Gut 1992; 33: 331-5.

3 Florent C, Cortot A, Quandalle P, Modigliani R, Sarfati E, Valleur R, et al. Placebo-controlled trial of Claversal in the prevention of early endoscopic relapse after 'curative' prevention of early, endoscopic relapse after 'curative' resection.

4 Rutgeerts P, Geboes K, Vantrappen G, Kerremans R, Coenegrachts JL, Coremans $G$. Natural history of recurrent Crohn's disease at the ileocolonic anastomosis after curative surgery. Gut 1984; 25: 665-72.

5 Dvorak AM, Monahan RA, Osage JE, Dickersin GR. Crohn's disease: transmission electron microscopic studies. II. Immunologic inflammatory response. Alterations of mast cells, basophils, eosinophils, and the microvasculature. Hum Pathol 1980; 11: 606-19.

6 Gleich GJ, Frigas E, Loering DA, Wassom DL, Steinmuller D. Cytotoxic properties of the eosinophil major basic proD. Cytotoxic properties of the eosin

7 Wang JM, Rambaldi A, Biondi A, Chen ZG, Sanderson CJ, Mantovani A. Recombinant human IL-5 is a selective eosinophil chemoattractant. Eur $\mathcal{f}$ Immunol 1989; 19: 701-5.

8 Fujisawa T, Abu-Ghazaleh R, Kita H, Sanderson CJ, Gleich GJ. Regulatory effect of cytokines on eosinophil degranulation. F Immunol 1990; 144: 642-6.

9 Desreumaux P, Janin A, Colombel JF, Prin L, Plumas J, Emilie D, et al. Interleukin-5 messenger RNA expression by eosinophils in the intestinal mucosa of patients with coeliac disease. 7 Exp Med 1992; 175: 293-6.

10 Gleich JG, Adolphson CR. The eosinophil leukocyte: structure and function. Adv Immunol 1986; 39: 177-233.

11 Weller PF. The immunobiology of eosinophils. $N$ Engl f Med 1991; 18: 1110-8.

12 Colombel JF, Torpier G, Janin A, Klein O, Cortot A, Capron $M$. Activated eosinophils in adult coeliac disease: evidence for a local release of major basic protein. Gut 1992; 33: 1190-4.

13 Torpier G, Colombel JF, Mathieu-Chandelier C, Capron M, Dessaint JP, Cortot A, et al. Eosinophilic gastroenteritis: ultrastructural evidence for a selective release of eosinophil major basic protein. Clin Exp Immunol 1988; 74: 404-8.
14 Dvorak AM, Onderdonk AB, McLeod RS, MonahanEarley RA, Antonioli DA, Cullen J, et al. Ultrastructual identification of exocytosis of granules from human gut eosinophils in vivo. Int Arch Allergy Immunol 1993; 102: 33-45.

15 Choy MY, Walker-Smith JA, Williams CB, MacDonald TT. Activated eosinophils in chronic inflammatory bowel disease. Lancet 1990; 336: 126-7.

16 Butterworth AE, Sturrock RF, Houba V, Mahmoud AA, Sher A, Rees PH. Eosinophils as mediators of antibody dependent damage to schistosomula. Nature 1975; 256: $727-9$.

17 Janin A, Torpier G, Capron M, Courtin P, Gosselin B. Immunological study of eosinophils in eosinophilic granuloma of bone: evidence for release of three cationic proteins and subsequent uptake in macrophages. Virchows Archiv A Pathol Anat 1992; 421: 255-61.

18 Janin A, Torpier G, Courtin P, Capron M, Prin L, Tonnel $\mathrm{AB}$, et al. Segregation of eosinophil proteins in alveolar macrophage compartments in chronic eosinophilic pneumacrophage compartments in ch

19 Moy JN, Gleich GJ, Larry LT. Non cytotoxic activation of neutrophils by eosinophil granule major basic protein. Effect of superoxide anion generation and lysosomial enzyme release. $\mathcal{F}$ Immunol 1990; 145: 2626-32.

20 Lucey DR, Nicholson-Weller A, Weller PF. Mature human eosinophils have the capacity to express HLA-DR. Proc Natl Acad Sci USA 1989; 86: 1348-51.

21 Mawhorter SD, Kazura JW, Boom WH. Human eosinophils as presenting antigen-cells: relative efficiency for superantigen- and antigen-induced $\mathrm{CD} 4+\mathrm{T}$-cell proliferation. Immunology 1994; 81: 584-91.

22 Spry CJ, Kay AB, Gleich GJ. Eosinophils. Immunol Today 1992; 13: 384-7.

23 Breese E, Braegger CP, Corrigan CJ, Walker-Smith JA, MacDonald TT. Interleukin-2 and interferon gamma secreting $\mathrm{T}$ cells in normal and diseased human intestinal mucosa. Immunology 1993; 78: 127-31.

24 Peltz G. A role for CD4+ T cell subsets producing a selective pattern of lymphokines in the pathogenesis of human chronic inflammatory and allergic diseases. Immunol Rev 1991; 123: 23-35.

25 Radford-Smith G, MacGowan I, Jewell DP. Th1 and Th2 cytokine gene expression in inflammatory bowel disease. Gastroenterology 1994; 106: A757.

26 Murray HW, Miralles GD, Stoeckle MY, McDermott DF. Role and effect of IL-2 in experimental visceral leishmaniRole and effect of IL-2 in experimen

27 Zhu Y, Lukacs NW, Boros DL. Cloning of THO- and TH2type helper lymphocytes from liver granulomas of Schistosoma mansoni-infected mice. Infect Immun 1994; 62: 994-9.

28 Gurbindo C, Russo P, Sabbah S, Lohoues MJ, Seidman E. Interleukin 2 activity of colonic lamina propria mononuclear cells in a rate model of experimental colitis Gastroenterology 1993; 86: 964-72. 